\title{
The promotion dilemma for clinician teachers
}

\author{
Rick Penciner, MD, $\mathrm{MSc}^{* \dagger}$
}

"When are you going for promotion?"

This question is asked repeatedly of clinical faculty in hospital hallways and the offices of departmental chairs and chiefs. I have been asked this question on more than one occasion and admit to having asked some colleagues this same question. For clinician teachers (many of whom are part-time faculty) whose primary focus is clinical care while teaching residents and medical students, academic promotion is often an afterthought filled with administrative busy work. We know that clinician educators and teachers do not get promoted at the same rates as clinician investigators and scientists. ${ }^{1}$ For a non-tenured track clinician teacher, promotion appears to have few if any benefits-or does it?

The intent of this article, through my personal reflections, is to reveal some of the inequities and challenges in the academic promotion process while still recognizing the benefits. I hope to disseminate in a scholarly manner-the challenges with the current system - and, thereby, start a conversation with academic leaders about adapting and changing the promotion process. The article finishes with a "call to arms" to consider more meaningful metrics for clinician teachers navigating academic promotion.

One of my faculty roles is to support other faculty members through the academic promotion process. For the most part, this means convincing them why they should "go for promotion." At the same time, I often struggle with my own academic promotion, "why." There are many benefits of promotion from institutional to individual. We certainly know that promotion does not mean more pay. However, promotion, whether at a junior level (to assistant professor) or senior level (to associate or full professor) benefits academic and clinical departments by demonstrating academic productivity. Many departmental chairs and chiefs use these metrics as key performance indicators of success. Departments (both academic and clinical) with a significant number of faculty moving through the ranks add a degree of legitimacy to not only their department but also the discipline. We all should want to be members of a club with high standards. There is potential for an enhanced reputation locally and nationally, attracting the most talented physicians and brightest learners. This enhanced reputation might also extend to the community, attracting funding and philanthropy. In addition, "promotion" involves rigorous, objective criteria by which faculty can be judged.

There are also benefits to the individual. Promotion provides recognition for the individual faculty member of their academic accomplishments. It may afford the faculty member the opportunity to engage in new types of professional work, such as consultancies and other academic roles. The actual promotion process, though tedious, allows for reflection, taking stock of where we have been and where we want to go with our careers. Academic appointments and promotion enhance our reputation amongst patients and their families. My patients have often been impressed that I am a "professor" at the university. Further, if for no other reason, being promoted will make my mother proud.

Do our clinician teachers value promotion? Through anecdotes and surveys, we understand that our clinician teachers do in fact value being promoted. So, why do so many of our faculty, specifically clinician teachers, struggle with academic promotion? Recently, Irby and O'Sullivan $^{2}$ describe the inequalities between how researchers and educators are rewarded. They recommended and advocated for a change to how we value and reward education roles and education scholarship.

However, I do not believe that many of our clinician teachers fit into this role of "educator" described by Irby and O'Sullivan. Our clinician teachers in academic

From the *Division of Emergency Medicine, Department of Family \& Community Medicine, University of Toronto, Toronto, ON; + North York General Hospital, Toronto, ON; and ¥Schwartz/Reisman Emergency Medicine Institute, Toronto, Canada

Correspondence to: Dr. Rick Penciner, North York General Hospital, 4001 Leslie Street, North York, ON M2K 1E1; Email: Rick.Penciner@nygh.on.ca 
health science centres and community teaching hospitals are the backbones of the education system for medical students and residents. They often do not develop curriculum, direct courses, or engage in education scholarship. Many of our clinician teachers teach primarily at the bedside or in small groups for the "love of teaching." They have a sense of social accountability in teaching the next generation of physicians. They teach because it adds interest and variety to what they do. They teach because they are of the belief that it makes them better clinicians and improves the care of their patients.

Clinician teachers probably value academic promotion but are often reluctant to admit it. They may fear not "measuring up" if unsuccessful. They may be reluctant to start a process with many barriers and hurdles. Clinician teachers are faced with an incredible administrative burden when applying for promotion. They often do not have the necessary support (including protected time and administrative support) to go through the process. Promotion manuals are often complex with detailed frameworks and guidelines designed primarily for researchers.

Promotion guidelines certainly do have criteria for promotion based on teaching and education. These criteria often include the demonstration of "teaching quality and quantity." For clinician teachers to be promoted, they typically require extensive and highly rated "teacher evaluation scores." However, there are numerous flaws in the use of teacher evaluation scores for promotion. Promotion manuals often require documentation that "ranks the candidate's teaching in comparison to their peers." The implication is that only those in the top ranks will be promoted. Based on this approach, only a minority of teachers will ever be promoted. In our experience, most clinical teaching is considered "very good" to "excellent." How does a "very good teacher" get promoted if she never reaches the level of "excellence" or the top 5\% as compared with her peers?

Do teacher evaluation scores actually assess the quality of teaching? The evidence tells us otherwise. Student evaluation of teaching is, in fact, an inadequate assessment tool for evaluating faculty performance. ${ }^{3}$ These evaluations probably measure a degree of learner satisfaction and teacher popularity rather than teacher impact or learning. There are also numerous process issues with our learners completing teacher evaluations on the faculty. Recently, I provided some challenging and difficult feedback to a resident that was performing below expectations. I could not help but think how my feedback and subsequent learner assessment would affect his evaluation of my teaching. Our learners already have a significant survey or evaluation fatigue. As a result, rates of completion of teacher evaluations are quite low and may not reflect the episodic teaching and encounters with our learners.

Therefore, how do we measure the impact of a teacher? Is quality more important than quantity? Impact certainly is the buzzword used everywhere from department and faculty strategic plans to promotion criteria. Measuring the impact of a clinical teacher is quite challenging. What we do know though is that teacher evaluation scores do not reflect impact. Traditional scholarship in the form of peer-reviewed publications does not necessarily translate to impact. As I reflect with pride on a published peer-reviewed article on an education topic, I am quickly humbled with the realization that probably only a few hundred people have read it. In contrast, I have recorded a podcast on the same topic that has been downloaded over 42,000 times around the world. Which is more impactful?

Maybe it is time to consider new and more meaningful metrics of teacher impact. If, as a teacher, I can influence one student who becomes an academic physician and, in turn, influences many of her students: is that significant impact? How does this compare to a teacher who has won a teaching award? Some of my most gratifying experiences as a teacher have come, when years later, I met former students (who are now practising physicians), and they tell me how impactful my teaching was. Perhaps it is these non-scientific testimonials and stories that we should be using to measure impact. Perhaps it is colleagues and peers who can share stories or assessments of the quality of my teaching. In my role as a faculty adviser, I have encouraged fellow clinician teachers to keep any and all evidence related to their teaching impact. This can range from the traditional evaluation summaries to emails from colleagues and learners describing the impact of their teaching and scholarly work. If this email is from across Canada or the United States, the faculty member can now describe the national and international impact.

Academic promotion for clinician teachers is full of challenges, the greatest of which is the process itself. Despite this, there are many benefits both intrinsic and extrinsic that make the aspiration and achievement of 
promotion worthwhile. For now, I will continue to encourage, cajole, and support my colleagues through the promotion process. As for my promotion journey, when the time is right, I will "go for promotion."

Acknowledgements: The author would like to thank Dr. Risa Freeman for her thoughtful review and feedback of the manuscript.

Competing interests: None declared.

Keywords: faculty, promotion, teacher

\section{REFERENCES}

1. Beasley BW, Simon SD, Wright SM; The Prospective Study of Promotion in Academia (Prospective Study of Promotion in Academia). A time to be promoted. 7 Gen Intern Med 2006;21(2):123-9.

2. Irby DM, O'Sullivan PS. Developing and rewarding teachers as educators and scholars: remarkable progress and daunting challenges. Med Educ 2018;52(1):58-67.

3. Hornstein HA, Law HF. Student evaluations of teaching are an inadequate assessment tool for evaluating faculty performance. Cogent Education (Internet). 2017;4(1). Available at: https://www.tandfonline.com/doi/full/10.1080 /2331186X.2017.1304016 (accessed June 6, 2018). 